\section{LA SEGURIDAD DEL TRABAJO EN LA CONSTRUCCION}

\author{
Ventura Rodríguez \\ Arquitecto Técnico
}

$750-1$

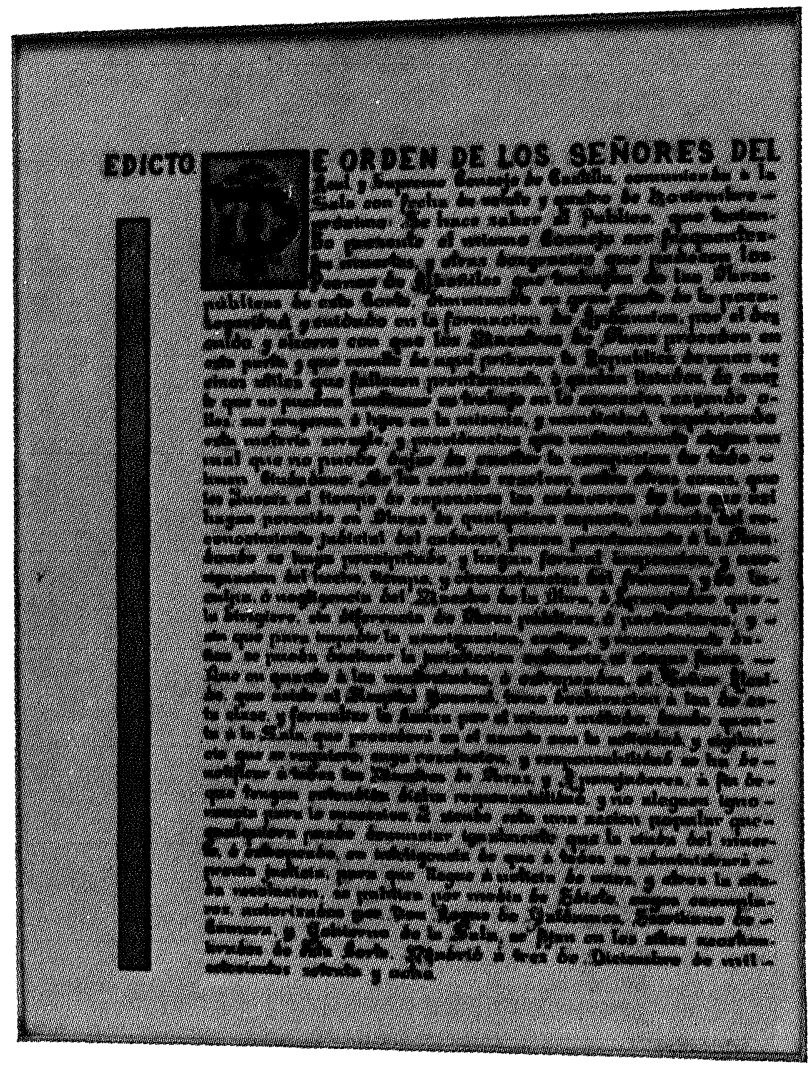

\section{INTRODUCCION}

Recojo con sumo agrado la invitación que me ofrece la revista "Informes de la Construcción», para escribir sobre un tema de tan triste y permanente actualidad en nuestro país como es el de las condiciones de seguridad en que se desarrolla el trabajo de la construcción, y que tan directamente me afecta como profesional, ya que, entre mis atribuciones profesionales, figura claramente la de velar por el buen cumplimiento de las normas que sobre esta materia están establecidas.
Quiero agradecer la colaboración que, para la redacción de este trabajo, he recibido de la Comisión de Tecnología del Colegio oficial de Aparejadores y Arquitectos Técnicos de Madrid, que me honro en presidir, $y$ que viene desde hace varios años trabajando para tratar de mejorar las condiciones, tanto legales como técnicas, en que se desenvuelve el tema que me ocupa.

Evidentemente, el tema podía enfocarse y tratarse desde muy diversos ángulos y distintas maneras; entre ellas he elegido la de exponer una panorámica general bajo todos los aspectos, de cuál es la situación actual y cuál sería a mi juicio la evolución deseable en aras a mejorar el sistema y, como consecuencia, reducir el índice de siniestralidad, meta a la que, en definitiva, deben ir encaminados todos nuestros esfuerzos.

\section{SITUACION ACTUAL DE LA SEGURIDAD EN LA CONSTRUCCION}

\subsection{Realidad de la actividad constructora}

Cualquier profesional de la construcción, e incluso personas ajenas a la actividad, puede constatar la evolución que ha sufrido el sector en los últimos quince años. Se han mejorado notablemente los medios mecánicos, así como el grado de industrialización, lo que, unido a los indudables avances tecnológicos, permite acometer obras de mayor envergadura, empleando maquinaria de mayor complejidad y nuevos sistemas constructivos, con mayor empleo cada vez de materiales prefabricados 0 , al menos, simplificando la intervención de la mano de obra en la propia ejecución de la misma, si bien ésta debe ser cada día más especializada.

A raíz de lo anterior, aparecen dos primeros factores dignos de análisis que inciden de una manera bastante directa en la siniestralidad del sector:

\subsubsection{Formación profesional del sector}

Se ha de reconocer, que todavía el nivel profesional del personal obrero que interviene en el proceso edificatorio, sigue siendo el más bajo de todo el espectro industrial, ya que gran parte de la mano de obra, sobre todo la de las primeras etapas de la construcción, previas a las instalaciones, suele ser de una escasa o nula formación profesional y de muy baja formación cultural.

Esto crea toda una serie de problemas humanos $y$ socio-económicos, como los de un bajo nivel retributivo y difícil adaptación al medio de trabajo lo que, unido a tener que soportar las condiciones climatoló- 
gicas permanentemente y a la constante sensación de provisionalidad que da la movilidad del centro de trabajo, hacen que sea muy difícil la labor de mentalización de prevención del posible accidente y consecuente adopción de medidas de protección, no ya colectivas, sino ni siquiera personales.

En general puede decirse que existe un absoluto desprecio a cuantificar y cualificar las posibilidades de suceso del accidente por parte de la gran mayoría del personal trabajador.

\subsubsection{Grado de profesionalidad de las empresas}

Tal vez, una legislación poco estricta, y una excesiva permisividad, desbordada en los años del desarrollo económico, ha permitido la proliferación de todo tipo de empresas o constructoras individuales, que salvo en el caso de las de mayor capacidad de producción, carecen generalmente de la infraestructura técnica necesaria y de los medios materiales adecuados así como de la capacidad organizativa precisa para prestar una mínima atención al problema de la Seguridad e Higiene en el Trabajo. Esto, unido a que, evidentemente y en un principio, la prevención supone un costo adicional que no se contempla como tal en el presupuesto de la obra, sino diluido en unos medios auxiliares nunca bien definidos y siempre aquilatados para ser más competitivos, hacen que desgraciadamente la seguridad e higiene sean para estas empresas como la cenicienta de toda su actividad constructora, para las que nunca llega el presupuesto.

\subsubsection{El factor humano}

Queda otro punto que analizar, posiblemente intangible, hasta filosófico si se quiere, pero que existe realmente, y es lo que se podría denominar como el "factor humano" ante el suceso del accidente. La enfermedad profesional o el accidente de trabajo, no sólo afectan al propio sujeto que lo padece, sino a todo el proceso productivo, familiares, compañeros de trabajo, empresa, y, en definitiva, a toda la sociedad con un costo no solamente económico (que luego se analizará) sino humano y sicológico, que influye directamente en el comportamiento futuro del obrero que ha sufrido el accidente.

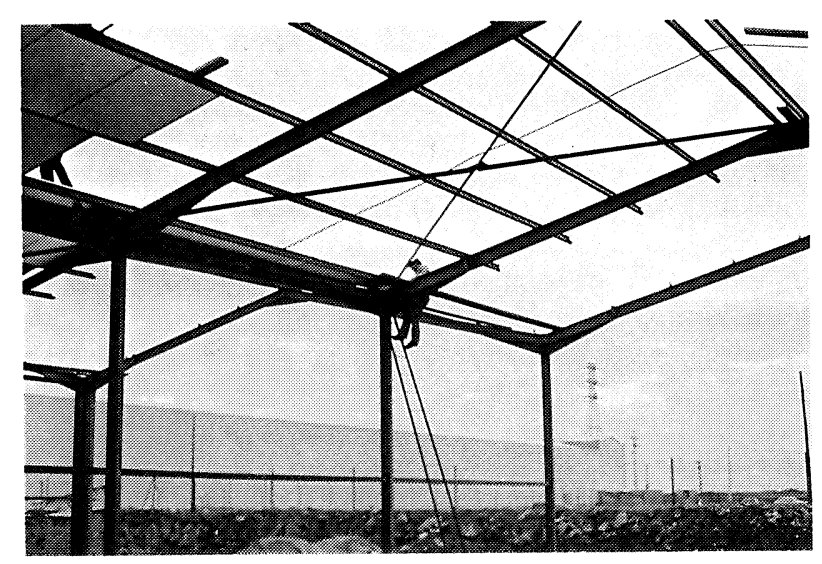

De ahí, lo importante no es solamente estudiar los medios y las medidas de protección para evitar el accidente, sino crear auténtica mentalidad prevencionista en todos los que, de una u otra manera, intervenimos en el proceso productivo de la construcción.

\subsection{Legislación actualmente vigente}

Como no soy jurista no pretendo hacer un estudio exhaustivo de la legislación actual en esta materia, sino sólamente enunciar los textos legales actualmente vigentes que de una $u$ otra manera, $y$ en su totalidad o en parte, se ocupan de este tema, así como realizar un ligero análisis de los mismos y aludir a la renovación y actualización que a mi juicio precisan.

\subsubsection{Textos legales}

- Constitución Española (Art. 40-2).

- Estatuto de los trabajadores.

- Reglamento de los Servicios Médicos de Empresa de 21 de noviembre de 1959.

- Reglamento de Seguridad e Higiene del Trabajo en la Construcción y Obras Públicas de 20 de mayo de 1952.

- Ordenanza de Trabajo para las Industrias de la Construcción, Vidrio y Cerámica de 28 de agosto de 1970 (Cap. XVI dedicado a Seguridad e Higiene).

- Ordenanza General de Seguridad e Higiene en el Trabajo, de 9 de marzo de 1971.

- Decreto sobre Comités de Seguridad de 11 de marzo de 1971.

- Reglamento electrotécnico de Baja Tensión, de 20 de septiembre de 1973.

- Reglamento de aparatos elevadores para obras de 23 de mayo de 1977.

- Normas técnicas sobre homologación de materiales de protección que dicta periódicamente el Ministerio de Trabajo.

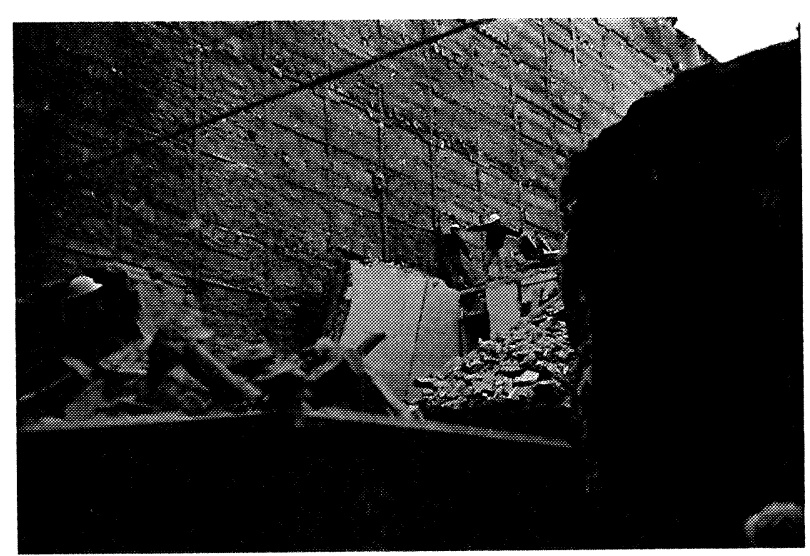


- Regulación que de esta materia hacen periódicamente los Convenios Colectivos del Sector en cada provincia.

Evidentemente existen otros textos de inferior rango y para aspectos muy específicos, que sería muy prolijo señalar.

\subsubsection{Análisis de la legislación vigente}

Sin entrar en un estudio pormenorizado, sí quisiera apuntar dos extremos que me parecen interesantes: uno, en cuanto a la fecha de las principales Normas; como se ve, las dos ordenanzas básicas, la del sector y la de seguridad, tienen más de 10 años de antigüedad, sin haber tenido ninguna regularización ni revisión posterior, lo que evidentemente hace que no hayan evolucionado conforme al desarrollo operado en el sector de la construcción. Más importante que el anterior, a mi juicio, es la falta de una ordenanza específica de Seguridad e Higiene en el Trabajo para la Industria de la Construcción, como la antigua del año 52, que aunque no de una manera específica puede considerarse absorbida y derogada por la posterior Ordenanza General del 71 y que realmente sería preciso estuviese actualizada.

Tienen también, las principales normas comentadas, un punto negativo de coincidencia y es el contener una serie de normas realmente no muy concretas, sin definiciones precisas y por lo tanto sin dar respuesta adecuada a los problemas específicos que se presentan en el proceso edificatorio. Así, por ejemplo, la Ordenanza General de Higiene y Seguridad, por tener que abarcar toda la problemática del trabajo en general, incide con escasa profundidad en el tema específico de la Construcción, que, dada la especialización y peculiaridad del medio en lo que a centros de trabajo y medios auxiliares se refiere, se ve prácticamente tratada y siempre de una forma genérica y casi nunca puntual.

En cuanto a la Ordenanza de Trabajo en la Industria de la Construcción, precisamente por su rango de ordenanza laboral, dedica solamente un capítulo a la materia de seguridad e higiene, lo que hace que el tratamiento del tema tampoco posea la debida profundidad, presentando más bien una serie de normas generales. Normas que casi siempre enuncian

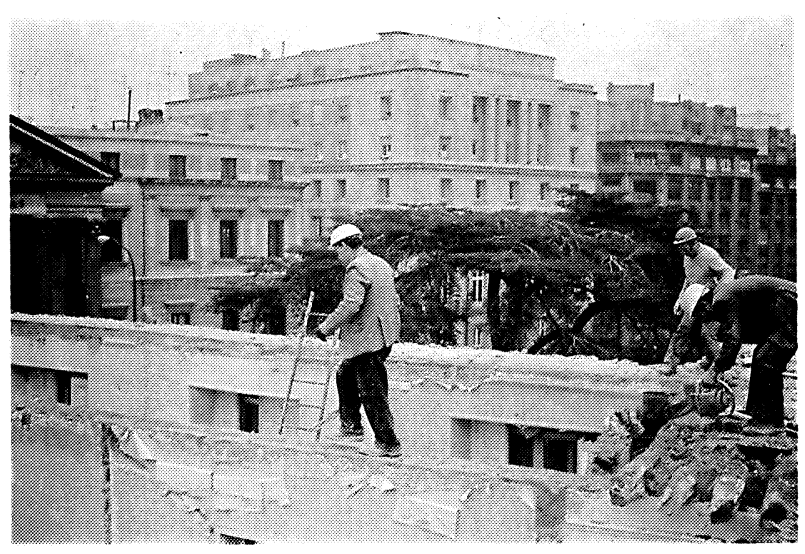

una posible sitủación de peligro que se debe evitar, pero que muy pocas veces describen la forma precisa de realizarlo en cada caso, con qué materiales y con qué medios.

Estudia el problema de la seguridad compartimentándola en los diversos medios auxiliares que intervienen en el proceso de edificación, como medios de elevación, andamiajes, barandillas, etc., pero no analiza las diversas fases de una obra, las distintas situaciones de riesgos más frecuentes que en cada una se dan y las correspondientes medidas preventivas para cada caso específico; es decir, falta una auténtica mentalidad preventiva para cada situación posible de riesgo.

\subsection{Organismos oficiales competentes en la materia}

En dos grandes organismos se concentra toda la responsabilidad del Estado en este área, que son la Inspección del Trabajo y el Instituto Nacional de Seguridad e Higiene en el Trabajo. El primero integrado en el Ministerio de Trabajo y el segundo, como Organismo Autónomo, dependiente también del mismo Ministerio.

\subsubsection{La inspección del trabajo}

Como se desprende de su propia titulación es el organismo encargado del control, vigilancia e inspección en los distintos lugares de trabajo, del cumplimiento de la normativa vigente en materia de seguridad e higiene, amén de la supervisión del buen funcionamiento de las relaciones laborales en general entre empresarios y trabajadores, tema sobre el que no incidiré por alejarse de nuestra cuestión.

Sus funciones en la materia que nos ocupa están claramente determinadas en el artículo $4 .^{\circ}$ de la Ordenanza de Higiene y Seguridad en el trabajo. En forma breve pueden resumirse en las siguientes:

- Vigilar el cumplimiento de la ordenanza.

- Prestar su asesoramiento para evitar o reducir riesgos.

- Emitir informes respecto a la prevención de riesgos.

- Cursar informes a las Magistraturas de Trabajo

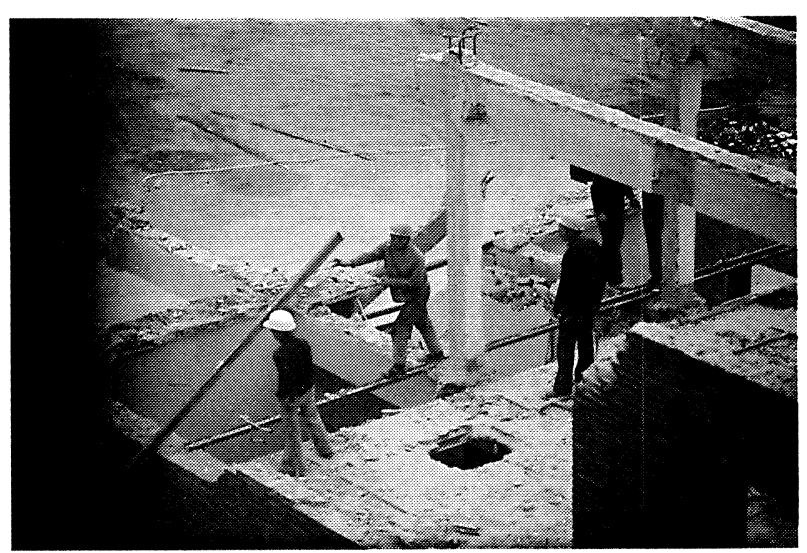


sobre accidentes de trabajo, así como a las Delegaciones del Ministerio.

- Acordar la suspensión de los trabajos cuando exista peligro grave para la salud de los trabajadores.

- Proponer la imposición de multas por infracción de las ordenanzas.

De tan amplias funciones debe reconocerse que tan solamente, en la mayoría de los casos, se cumple la sancionadora. Es decir, al menos en el campo de la Construcción, que es el que nos ocupa, la labor de la Inspección del Trabajo se reduce a una visita a la obra correspondiente de forma muy breve, resultado de la cual invariablemente se sabe que se producirá una sanción, evidentemente justificada, por la falta de algún medio o prenda de protección, pero que no corresponde a una situación realmente estudiada e inspeccionada. $Y$ esto, cuando se produce tal visita, porque son mayoría las obras que se inician y concluyen $\sin$ que hayan recibido nunca la visita de la Inspección de Trabajo, debido a la falta de medios humanos que aqueja al servicio. Además, dichos medios, generalmente están constituidos por profesionales que poco o nada tienen que ver con la actividad industrial que deben inspeccionar, es decir, habitualmente no suelen ser técnicos en las diferentes materias, sino licenciados en cualquier rama de humanidades, como Derecho, fundamentalmente.

Toda la anterior situación hace que esa labor de vigilancia y prevención del accidente, que claramente tienen asignada, se convierta casi siempre en la mera función inspectora y sancionadora, sin ningún resultado práctico de tipo prevencionista, y sí con el único de transformar la visita a una obra en una multa económica para el empresario.

\subsubsection{Instituto Nacional de Seguridad e Higiene en el Trabajo}

Nacido como consecuencia de los Planes Nacionales de Seguridad e Higiene del Trabajo, vino a sustituir a los Consejos Provinciales. Sus atribuciones realmente pueden verse recogidas en los artículos 5 y 6 de la mencionada Ordenanza General.

Es un organismo que, al contrario del anterior, tiene como misión fundamental la de prevenir el accidente, mediante el estudio de los medios más adecuados de seguridad en cada caso concreto.

Para ello, aparte de sus propios técnicos y medios de documentación e investigación, programa periódicamente con un extenso temario, actividades de formación a todos los niveles para divulgar las técnicas de la prevención de accidentes mediante Cursos de diversa extensión y contenido, Seminarios, Mesas Redondas, etc.

Es sin duda la entidad oficial que, según mi criterio, en la actualidad más aporta a la mejora de los sistemas de protección y prevención de los accidentes en el trabajo, por lo que juzgo interesante el reseñar brevemente su estructuración y funcionamiento.

Consta de un Organo Central donde radica la dirección y coordinación general del Instituto. Dependiendo de este órgano, se subdivide el territorio nacional en cuatro áreas, cada una de ellas dependientes de los Centros de Investigación y Asistencia Técnica (anteriormente llamados Institutos Territoriales) que radican en Madrid, Barcelona, Bilbao y Sevilla. Cada uno de estos centros tiene, además de los cometidos generales del Instituto, específicamente los siguientes:

- Madrid = Formación y docencia.

- Barcelona $=$ Servicios de documentación y publicaciones.

- Bilbao = Contaminación ambiental.

- Sevilla $=$ Homologación de medios y prendas de protección personal.

Independiente de estos centros, en cada provincia española existe un Gabinete Técnico Provincial, que desarrolla toda la labor de asesoramiento, informes, etc., que tiene encomendado el Instituto.

Esta es de forma esquemática la estructuración del Instituto, pero ¿cómo funciona y qué misiones realiza?

Fundamentalmente, la que se ha indicado con anterioridad de prevención del accidente mediante el estudio, investigación e información sobre medios de protección. En nuestro campo específico de la Construcción concede los permisos de iniciación de una obra de nueva planta, para lo cual sus técnicos visitan previamente la misma, inspeccionando las instalaciones provisionales; así como a lo largo de la ejecución de la obra realizan periódicas visitas, no de inspección, sino de asesoramiento e información de cómo se encuentran los medios y materiales de prevención, tomando buena nota de aquellas situaciones peculiares que por su dificultad precisen de un estudio posterior sobre los medios o sistemas de seguridad a emplear, estudio que se realiza aportándose su solución posteriormente.

En caso de accidente y a requerimiento de la Inspección de Trabajo visitan la obra, emitiendo informe técnico sobre las causas posibles del mismo, tras la correspondiente investigación.

Esta labor, realizada en la propia obra, viene a completar lo expuesto anteriormente de formación hacia el exterior con la impartición de cursos y otras actividades docentes, para todos los niveles que intervienen en la construcción.

\subsubsection{Laboratorio de homologación de Sevilla}

Como se ha apuntado anteriormente, el Centro de Investigación de Asistencia Técnica de Sevilla tiene encomendado, dentro del organigrama del Instituto, la labor de la investigación de medios y prendas $y$ sistemas de protección personal, para lo cual cuenta 
Informes de la Construcción/346

con un completo laboratorio donde, tras los estudios y ensayos necesarios, se concede la homologación de determinada prenda o medio de protección que serán presentados por las empresas que fabrican estos productos; naturalmente, basados en la normativa que sobre dicha homologación promulga periódicamente el Ministerio de Trabajo (Normas M.T.), precisamente como fruto de los estudios e investigaciones que realiza el laboratorio.

Es preciso comentar en este punto que, una vez emitidas las normas anteriores, éstas son de obligado cumplimiento $y$, por lo tanto, cuando se ha producido la homologación de una determinada prenda o medio de protección, no está permitido el uso de ninguna otra que no haya obtenido dicho requisito o al menos que no demuestre encontrarse en tramitación si se trata de una norma reciente.

\subsection{Otras organizaciones implicadas}

Aunque de una forma oficial tan solamente los dos organismos citados anteriormente, integrados en el Ministerio de Trabajo - amén de la propia estructura del Ministerio-, son competentes para todo lo relacionado con esta materia, es evidente que otras organizaciones también tienen algo que decir en el tema que nos ocupa. De entre todas ellas trataré algunas a continuación, sin pretender exponer un estudio exhaustivo sino tan sólo explicar el papel que cada una de ellas desempeña.

\subsubsection{Centrales sindicales}

Cada una de las centrales mayoritarias poseen, en su organigrama, departamentos concretos sobre salud laboral o medicina del trabajo que se preocupan y estudian las mejoras posibles a introducir en los sistemas y medios de protección en el trabajo y, lo que es más importante, la posible eliminación de riesgos y la prevención de las enfermedades profesionales, mediante el estudio de los mejores métodos de trabajo o de las condiciones en que éstos se desarrollan.

Pero ante esta positiva función cabe criticar la falta, en general, de comunicación al personal obrero de las obligaciones y derechos que en materia de seguridad e higiene les otorga la legislación vigente, principalmente en empresas medias y pequeñas.

No se ejerce debidamente la labor de mentalización y formación de dicho personal en esta materia, adoptando casi siempre una postura de autodefensa ante las carencias de medios de las empresas constructoras, es decir, reclamando, en justicia casi siempre, sus derechos como trabajadores a las adecuadas medidas de protección colectiva, pero exigiendo muy pocas veces las obligaciones que en medios de protección personal deben usar esos mismos trabajadores.

Ya se ha visto anteriormente la importancia de que sea el propio trabajador el que se sienta concienciado de la necesidad de exigir y usar todas las medidas preventivas que las empresas deben poner a su disposición, y el uso adecuado que de las mismas debe ejercer, y esto no siempre se cumple ni es asumido plenamente por las centrales sindicales, que como norma general pretenden eximir de responsabilidad al trabajador en perjuicio de la responsabilidad de la empresa.

El mejor ejemplo de lo que digo es el tratamiento que en los diversos convenios colectivos del sector se da a la materia que nos ocupa. Suele, casi siempre, quedarse en una mera referencia a la necesidad de cumplir la legislación vigente y a ciertas reivindicaciones de mejoras por parte de los trabajadores, en cuestiones no siempre fundamentales como ropa de trabajo, calentadores de comida y una alusión a la debida regulación de la creación de los vigilantes y comités de seguridad en las obras, no siempre seguida por los sindicatos; lo que, sin dejar de ser importante, evidentemente no exime de la necesidad de reivindicación en otros aspectos más fundamentales.

\subsubsection{Asociaciones patronales}

Al igual que las anteriores entidades comentadas, las asociaciones ompresariales de la Construcción cuentan con sus propios órganos de trabajo que se ocupan de esta materia y están presentes en cuantas iniciativas se promueven para mejorar las condiciones de seguridad e higiene, como campañas de mentalización, publicaciones, simposios, etc.

Pero la actitud de las empresas es muy dispar según se trate de las grandes constructoras del país, integradas en SEOPAN (Asociación de Empresas de Construcción y Obras Públicas de Ambito Nacional), o de las de tamaño mediano y pequeño, integradas en otras asociaciones patronales.

En el primero de los casos, casi todas ellas cuentan en sus organigramas con un departamento de Seguridad e Higiene en el Trabajo o de Medicina y Salud Laboral, que se encarga de redactar los Planes de Seguridad para cada obra, así como de vigilar su cumplimiento y de la creación de órganos de seguimiento de la seguridad, como los Comités de Seguridad o Vigilantes, en función del tamaño de la obra. Asimismo, en estas empresas grandes es relativamente normal el redactar planes de seguridad para las obras que realizan y el ocuparse del seguimiento de los mismos.

Desgraciadamente no se puede decir lo mismo de esa otra gran mayoría en el sector de pequeñas y medianas empresas, para las que en buen número de veces, estas cuestiones de seguridad e higiene en el trabajo no suponen nada más que un incremento en los costos de las obras que, en las actuales circunstancias del mercado, rara vez están dispuestas a asumir en su integridad.

De cualquier modo y para evitar una visión unipersonal de la actitud de estas asociaciones (tanto Sindicatos como Asociaciones Patronales) se insertan al final de este artículo unos breves cuestionarios formulados a 
las cuatro asociaciones más representativas, dos de los Sindicatos (CC. OO. y U.G.T.) y dos de Asociaciones Patronales (SEOPAN y AECOM).

\subsubsection{Mutuas patronales de seguros}

Sería injusto no resaltar aquí la generalmente positiva aportación que estas entidades realizan en el terna que nos ocupa, ya que su acción no se limita a la meramente aseguradora, con su obligada vertiente mercantil, sino que a través de sus organizaciones prestan asesoramiento y ayuda a las diversas empresas constructoras aseguradas en esta materia.

Estas ayudas se materializan en cursos de formación para el personal obrero, principalmente capataces, encargados y responsables de la seguridad en las obras; revisiones médicas para la prevención o detección de enfermedades profesionales; vigilancia y asesoramiento en las obras de las principales medidas de seguridad, etc.

Asimismo, estas entidades participan activamente, incluso con aportación económica, en cuantas campañas e iniciativas son promovidas por organismos tanto públicos como privados, para mejorar las condiciones de trabajo en el sector.

\subsection{Evolución estadística}

Trataré únicamente en este apartado de dar una visión general de la situación y no un estudio estadístico pormenorizado, que se escapa a las pretensiones del presente trabajo.

Aunque contemplando el cuadro siguiente puede parecer que la situación ha mejorado, esto es sólamente verdad en valor absoluto del número de accidentes, pero no así en su valor relativo, dada la disminución de la actividad constructora en las áreas temporales que se contemplan. Aun sin tener en cuenta este hecho, se observará que la disminución es sólo apreciable para el número de accidentes leves, pero no así para el de graves y mortales, que en el año 1981 casi se mantienen respecto a 1980 .

\begin{tabular}{|c|c|c|c|c|c|c|c|c|}
\hline \multirow{2}{*}{15} & & \multirow{2}{*}{$\frac{1978}{\text { NUMERo }}$} & \multicolumn{2}{|c|}{1979} & \multicolumn{2}{|c|}{1980} & \multicolumn{2}{|c|}{1981} \\
\hline & & & NUMERO & $\Delta \%$ & NUMERO & $\Delta \%$ & NUMERO & $\Delta \%$ \\
\hline \multirow{2}{*}{ LEVES } & Accidentes & 141.696 & 120.805 & $.14,9$ & 95.997 & $-20,5$ & 80.520 & $-16,1$ \\
\hline & 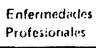 & 257 & 234 & $-8,9$ & 172 & -26.5 & 145 & $-15,7$ \\
\hline \multirow{2}{*}{ GRAVES } & Acciduturte: & 2.325 & 2.232 & $\cdots$ & 2.080 & $-6,8$ & 2.080 & 0.0 \\
\hline & 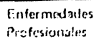 & 3 & 6 & - & 10 & 66.7 & 14 & $a n, 0$ \\
\hline \multirow{2}{*}{ MORTALES } & Accidentes & 335 & 286 & $-14,6$ & 234 & $-18,2$ & 230 & -1.7 \\
\hline & 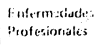 & .. & - & - & 1 & - & - & - \\
\hline \multirow{2}{*}{ TOTAL } & Accidentes & 144.556 & 123.323 & -14.7 & 98.311 & $-20,3$ & 82.830 & $-15,7$ \\
\hline & $\begin{array}{l}\text { Enffermedtades } \\
\text { Protesionzles }\end{array}$ & 260 & 240 & $-7,7$ & 183 & $-23,8$ & 159 & -13.1 \\
\hline
\end{tabular}

Accidentes en la industria de la construcción, en valores absolutos, con sus variaciones porcentuales.
Por ello, donde realmente se aprecia que, lejos de mejorar, la situación empeora, es en los gráficos 1 y 2 , donde se exponen los Indices de incidencia (li) para accidentes graves y mortales, respectivamente; y donde, comparada con otras ramas de actividad, la construcción no solamente ocupa un destacado primer lugar sino que muestra en ambos casos una evolución ascendente $y$, además, en una proporción superior al resto de las actividades. Esto se torna particularmente dramático en los accidentes mortales, en los que las demás ramas de actividad laboral vienen consiguiendo rebajar año a año sus índices, en tanto que la construcción, tras venir haciéndolo desde el año 77 al 80 , nuevamente en el 81 ve cómo vuelve a elevarse sustancialmente el número de accidentes mortales por número de trabajadores empleados.

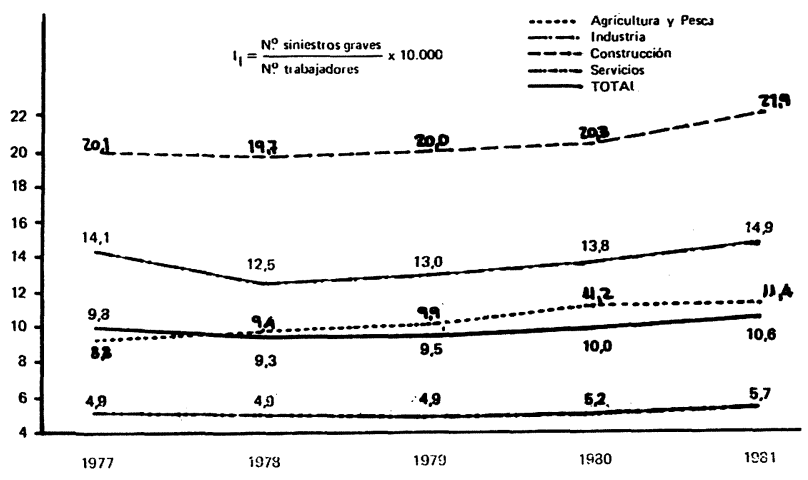

Gráfico 1.-Indices de Incidencia $\left(l_{1}\right)$ para siniestros graves en diversas actividades de la economía nacional.

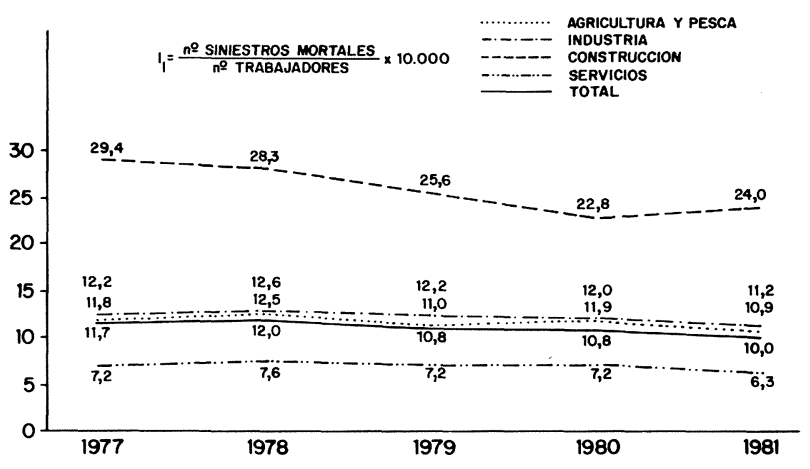

Gráfico 2.-Indices de Incidencia $\left(l_{1}\right)$ para siniestros mortales en las diversas actividades de la economía nacional.

Esto hace que también el Indice de gravedad (lg), que es el número de jornadas perdidas, por causa de accidente, en proporción al número de horas trabajadas por el sector y por 1.000 , sea para la construcción el más alto de todos los sectores económicos, con un 2,27 frente al 2,05 de la industria, 0,81 de la agricultura y pesca y 0,44 de los servicios; y muy por encima de la medida nacional, que es de 1,10.

Lo mismo cabe decir de la duración media de incapacidades (D.M.I.) que es el número de jornadas perdidas por accidentes con baja en el centro de trabajo, en relación con el número de accidentes con baja en dicho centro. Para la construcción, este índice, vuelve a ser el más alto de la economía nacional, con un 65,1 frente a la media nacional del 51,5 . 
Por último cabe decir que, incluso en valores absolutos y referidos al año 1981, en accidentes mortales la construcción, con sus 230 casos, representa el 20,9\% del total de la actividad económica y está a la cabeza de todas las demás ramas de actividad. En accidentes graves, con los 2.094 acaecidos, representa el 17,9\%, por debajo sólamente de la agricultura, pesca y silvicultura, que con 2.279 representa el $19,5 \%$ del total.

En fin, sin pretender ser catastrofista, ésta es la fría realidad de las cifras.

\section{RESPONSABILIDADES ESTABLECIDAS ANTE EL ACCIDENTE}

A la vista de todo lo anterior, es evidente que siempre que se produce un accidente y sobre todo cuando éste es mortal, no cabe otro remedio que preguntarse e investigar las posibles responsabilidades establecidas por la normativa vigente y las personas o estamentos depositarios de las mismas. Aunque es un tema realmente difícil y espinoso, no quiero eludir mi propia obligación de entrar en él.

\subsection{Tipo de responsabilidades}

Como consecuencia de los textos legales, antes mencionados, y de los superiores Códigos Civil y Penal, cabe extraer cinco tipos de responsabilidades, que son: las "penales" y "civiles", reguladas en los Códigos generales correspondientes; las "administrativas", reguladas fundamentalmente en todos los textos anteriormente relacionados; las "sociales", que se derivan del grado de jerarquía que se ocupe en el esquema de la producción y del grado de intervención en el proceso constructivo; y las "morales", que son, podríamos decir, aquellas que cada uno en conciencia quiera aplicarse también, en función de su grado de intervención en dicho proceso.

\subsection{Responsabilidades de los diversos participantes en el proceso constructivo}

Este cúmulo de posibles responsabilidades qe pueden derivarse del suceso de un accidente, unido a la confusa regulación que de las mismas hacen los textos legales aplicables, hace que sea muy difícil establecer claramente las competencias y escala de responsabilidades que corresponden a las personas y estamentos que, de alguna manera, intervienen en el proceso de la edificación. No obstante y para intentar clarificar, voy a indicar muy brevemente cómo vienen reguladas las actuaciones de cada una de las partes implicadas.

\subsubsection{Los trabajadores}

El artículo 11 de la Ordenanza General les obliga concretamente a usar correctamente los medios de protección y cuidar de su perfecto estado de conservación, así como a dar cuenta inmediata a sus superiores de las deficiencias y averías que puedan ocasionar peligros en cualquier puesto de trabajo $y$ solicitar los medios de protección personal de carácter preceptivo para la realización de su trabajo. En el Artículo 173 de la Ordenanza Laboral del sector se va más allá, al designar incurso en las responsabilidades a que hubiere lugar, al trabajador que no avisara a sus superiores de los riesgos o imperfecciones de las máquinas, herramientas de instalaciones y material que use, produciéndose por ello víctimas o daños. También el reciente Estatuto del Trabajador es muy claro al asignar, en su Artículo $4 .^{\circ}$, como derecho básico del trabajador el de su integridad física y el de una adecuada política de Seguridad e Higiene; y en su Artículo $5 .^{\circ}$, como deber básico, el de obsenvar las medidas de Seguridad e Higiene que se adopten, ampliándose posteriormente estos derechos y deberes dentro del Artículo 19 que dicho estatuto dedica a la Seguridad e Higiene.

Frente a estas obligaciones y derechos que conforman las responsabilidades "morales" y "administrativas" de los trabajadores, están reguladas las posibles sanciones en el Artículo 159 de la Ordenanza General.

\subsubsection{Los vigilantes o Comités de Seguridad}

Tienen reguladas sus actuaciones en el Artículo $8 .^{\circ}$ de la Ordenanza General (para los Comités) y en el 9. (para los vigilantes). Brevemente podríamos resumirlas en: Promover la observancia de las disposiciones vigentes, informar a los trabajadores sobre las normas de seguridad e higiene, investigar las causas de los accidentes, cuidar de que los trabajadores reciban formación adecuada en esta materia, promover campañas de divulgación de la Seguridad, etc. Estas actuaciones corresponden a los Comités de Seguridad; para los Vigilantes son las de comunicar a los superiores las situaciones de peligro, examinar las condiciones de orden, la limpieza de instalaciones, etc.

\subsubsection{El personal técnico y los mandos intermedios}

Vienen reguladas sus responsabilidades en el Artículo 10 de la Ordenanza General: cumplir y hacer cumplir a las personas a sus órdenes lo dispuesto en la Ordenanza, instruir al personal y prohibir o paralizar los trabajos de los que se deriven peligros inminentes de accidente. También el Artículo 174 de la Ordenanza Laboral del sector dispone como obligación del Jefe de Obra el intervenir inmediatamente remediando el defecto de cualquier máquina o instalación en caso de denuncia por parte de un trabajador, incurriendo en caso contrario en falta grave.

Estas personas se enfrentan a responsabilidades, por supuesto "morales", pero también "civiles" y hasta "penales", que vienen determinadas implícitamente en dos Artículos 152 y 154 de la Ordenanza General.

\subsubsection{La dirección facultativa}

$\mathrm{Ni}$ en la Ordenanza General ni en la Laboral del sector se menciona para nada la actuación de estos técnicos, tanto el Arquitecto como el Aparejador o Arquitecto Técnico. Sin embargo, son los técnicos con más duras responsabilidades en estos temas, de todos los que 
forman el proceso. Podríamos decir que son los "chivos expiatorios" que la sociedad ha encontrado para enjugar su propio defecto legislativo y la vigilancia de su cumplimiento en esta materia.

El Arquitecto (por ser el Director de la obra y absoluto responsable de la misma) y el Aparejador o Arquitecto Técnico (porque en sus atribuciones profesionales tiene muy claramente atribuida su «obligación de inspeccionar y controlar las instalaciones provisionales de la obra y las medidas de seguridad e higiene») son los técnicos que asumen responsabilidades de índole "moral", "social", "administrativa", "civil" y "penal", siendo por otra parte evidente que, en el desarrollo de su trabajo, no poseen de hecho medios eficaces para poder hacer frente a estas atribuciones, cuando se detectan faltas en las medidas de seguridad e higiene.

\subsubsection{Las empresas}

Las obligaciones de los empresarios están reguladas en la Ordenanza General en el Artículo 7. ${ }^{\circ}$ y van encaminadas, en general, a hacer cumplir la Ordenanza en toda su extensión y a cubrir todos los derechos de los trabajadores en esta materia, desde medios de protección a facilitarles la enseñanza. También la Ordenanza Laboral, en los Artículos 166 a 170, cubre aproximadamente los mismos objetivos anteriores.

En cuanto al Estatuto del Trabajador, en punto $4 .^{\circ}$ del Artículo 19, se explicita la obligatoriedad del empresario de facilitar información práctica en materia de seguridad a sus trabajadores. En este sentido, se pueden derivar para los empresarios responsabilidades de índole, por supuesto moral, pero también "sociales", "administrativas" y "civiles".

\subsubsection{La Administración}

Tiene también asignadas, como es natural, amplias competencias en la Ordenanza General de Seguridad e Higiene (Artículos 2 al 6) en la.que se regulan las actuaciones del Ministerio de Trabajo y de sus Delegaciones, la Inspección de Trabajo, Consejos Provinciales de Seguridad e Higiene y Consejos Territoriales. Tales actuaciones van desde dictar normas específicas para sectores que desarrollen la Ordenanza General, crear centros de estudio e investigación, contribuir a la formación teórico-práctica de las empresas, informar e

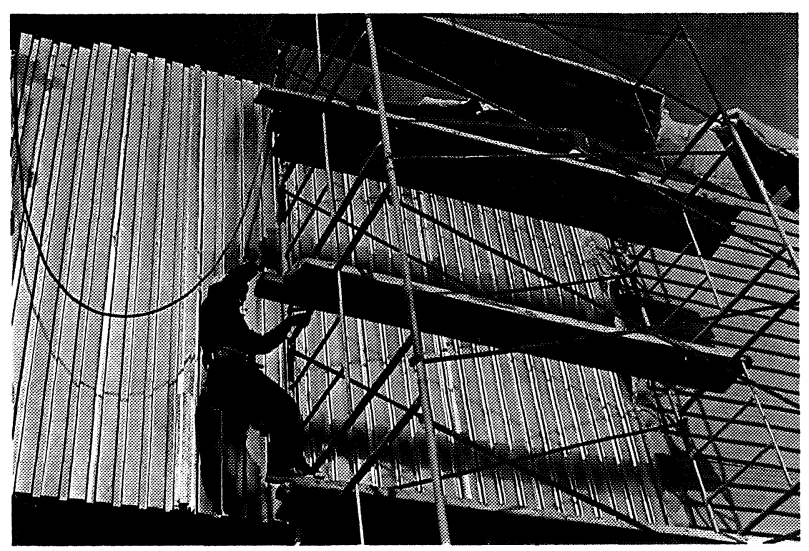

instruir a las mismas en estos temas, promover la investigación de causas de accidentes, etc., hasta las de vigilancia de cumplimiento de la Ordenanza, prestar asesoramiento para reducir el riesgo, etc., que tiene atribuidas la Inspección de Trabajo, pasando por toda una amplia gama de funciones que definen cuál debería ser la actitud de la Administración en esta materia. Evidentemente, la Administración tiene responsabilidades muy claras de índole "social" y "moral", deducidas de todas estas funciones.

\subsubsection{Análisis de las actuaciones}

Cabría ahora preguntarse, frente a todo este cúmulo de funciones y responsabilidades más o menos claramente definidas en nuestros textos legales, cómo se comportan de hecho cada una de las partes implicadas.

Si bien no es éste el momento de estudiar pormenorizadamente esta actuación, no es pecar excesivamente de derrotistas si se dice que prácticamente todas las partes implicadas, tanto a nivel personal como a nivel de entidades o estamentos, incumplen las funciones asignadas. Desde el trabajador que suele mostrar un desprecio sicológico hacia las situaciones de peligro y colabora escasamente en la utilización de los medios preventivos que a veces se le proporcionan, o bien no los reclama (como sería su obligación) antes de comenzar su trabajo, hasta la Administración, que ni con mucho cumple con sus labores de vigilancia y asesoramiento en el cumplimiento de esta materia, pasando por los empresarios que, salvo honrosas excepciones, no se preocupan de la creación de los Comités de Seguridad, ni del nombramiento de Vigilantes y escasamente de la formación de su personal en esta materia, y no siempre aportan a la ejecución de la obra las cantidades económicas que serían precisas para hacer frente correctamente a las medidas de seguridad. Sin olvidar los incumplimientos de los técnicos al frente de dichas empresas, en sus labores de Jefes de Obra o mandos intermedios, que a veces (las más, porque las empresas no les permiten los desembolsos que la buena actuación de la seguridad requiere; y otras porque están agobiados por el acoso de los plazos de terminación y de los costos de ejecución) tampoco se preocupan excesivamente de una buena actuación en materia de seguridad.

\subsection{Costo de la accidentabilidad}

Aunque cuantitativamente no sea fácil establecer un costo, ni mucho menos por sectores -es decir, trabajadores, empresarios, técnicos y sociedad en general- de la accidentalidad en la construcción, bien es cierto que de un razonamiento sencillo se deduce que para el trabajador hay un costo humano claro $y$ rotundo, basado en las anteriores estadísticas, lo que le supone en el peor de los casos, pérdida de la vida, $y$ en los accidentes con baja, unos días de pérdida de su salario real y, en definitiva, de su poder adquisitivo, al margen de las propias consecuencias fisiológicas que pudieran derivarse del accidente y toda la secuela de inestabilidad posterior en su puesto de trabajo. 
En cuanto al costo económico, es evidente que, en definitiva, la sociedad y el país en general pagan tan altos índices de accidentes de una manera u otra, bien sea a base de las cuotas que los empresarios deben abonar a las empresas aseguradoras por los altos índices de siniestralidad, bien sea por las prestaciones que la Seguridad Social debe abonar en concepto de accidentes o de enfermedades laborales, o en concepto de indemnizaciones, bien por accidente con baja, bien por defunción, etc.

\subsubsection{La seguridad cuesta dinero}

Una cosa es clara: de realizar una obra con todas las medidas de seguridad adecuadas, a no emplear ninguna, o muy pocas, hay una evidente diferencia de costo material. Su instalación, consenvación en condiciones adecuadas, recuperación, vigilancia, etc., cuesta dinero.

Lo anterior actúa de forma negativa a la hora de calibrar la competitividad de un presupuesto para edificar una obra, y en principio ningún promotor consulta este extremo cuando solicita presupuesto para una realización concreta. Entre otras cosas porque legalmente $-y$ esto lo saben muy bien las empresas constructoras- este costo está implícitamente incluido en cada una de las partidas de obra que se ofertan, ya que en el precio descompuesto de las mismas figuran como una parte integrante del costo material los medios auxiliares y la mano de obra indirecta, en los que lógicamente debe ir incluido el costo inherente a la Seguridad para la realización de esa partida, que la Normativa vigente obliga.

Además, de una manera clara y rotunda, la constructora acepta plenamente este extremo cuando, al comenzar la obra, firma en la primera hoja del Libro de Ordenes Obligatorio de la Dirección Facultativa, que conoce y asume plenamente la Normativa Legal vigente en materia de Seguridad en el Trabajo.

Por lo tanto y como conclusión podemos decir que el ahorrarse parte del dinero que cuesta la Seguridad supone una seria infracción a la legislación vigente. Al proceder así, lo que realmente se está haciendo es cobrar un sobrecosto en cada una de las partidas de obra, ya que realmente no se emplean esos recursos en Seguridad de forma suficiente.

\subsubsection{La Seguridad es rentable}

Con la misma fuerza que el anterior, este es un axioma, clásico cuando se habla de Seguridad, que está fehacientemente comprobado y contrastado con la realidad práctica.

Es posible que no lo sea para un ámbito pequeño de análisis, es decir, para una determinada obra, o una determinada empresa. Pero desde luego sí lo es para analizar la generalidad del sector $y$ de todos sus estamentos implicados.

\section{EVOLUCION QUE SERIA DESEABLE}

Analizando, aunque sólamente sea por encima, todo lo anterior, es evidente que el problema de la Seguridad e Higiene en el Trabajo de la construcción dista mucho de estar resuelto en la actualidad. Por ello voy a intentar exponer qué factores de corrección podrían introducirse, para tratar de paliar dicho problema.

\subsection{Adaptación de la legislación a la situación actual}

Como hemos visto anteriormente, la legislación actual no es precisamente la más completa ni adecuada para. la evolución que en los últimos años ha experimentado la construcción, si bien reconozco que tiene evidentemente partes muy positivas.

No obstante, creo que sería muy necesario establecer una nueva legislación, no ya de ámbito general a nivel de ordenanza del trabajo, sino específicamente en nuestro campo. Una legislación, como en su tiempo la hubo, de Seguridad e Higiene en el trabajo de la construcción, donde de la manera más concreta po: sible se especificaran todos los posibles riesgos que condicionan el trabajo y las correspondientes protecciones colectivas y personales, con espíritu prevencionista del accidente, intentando huir en todo lo posible de generalidades y concretando también, en todo lo posible, tanto los elementos a utilizar como su diseño, forma de instalación, mantenimiento, recuperación, etc.

También en esta nueva legislación debería de darse un mayor ímpetu a la labor de la Inspección de Trabajo, en el sentido de cumplir totalmente las atribuciones que actualmente tiene asignadas, mediante una mayor labor de vigilancia y un asesoramiento más extenso de lo que actualmente es y con menos sentido represivo y sancionador que el que tiene, de forma que pudiera establecerse una auténtica corriente de confianza entre la Administración (representada por la Inspección de Trabajo) y las empresas constructoras.

\subsection{Delimitación de responsabilidades y competencias}

Por último, sería imprescindible que la nueva legislación definiera, de una manera mucho más completa

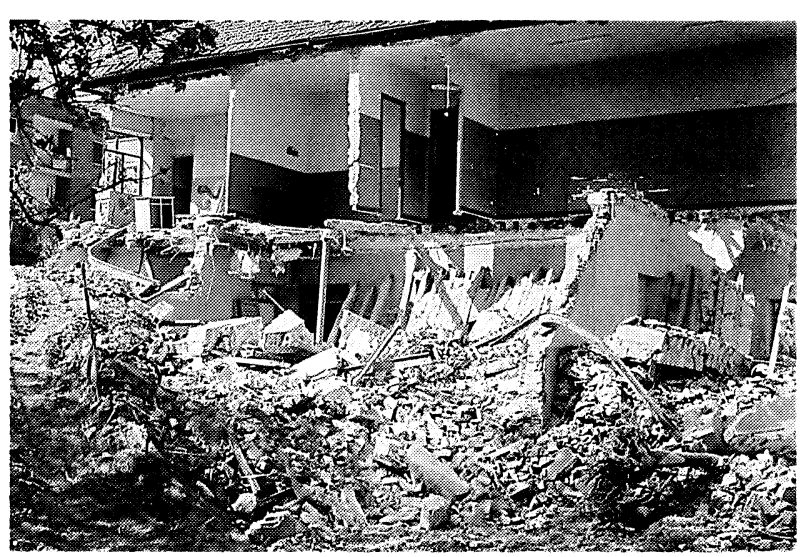




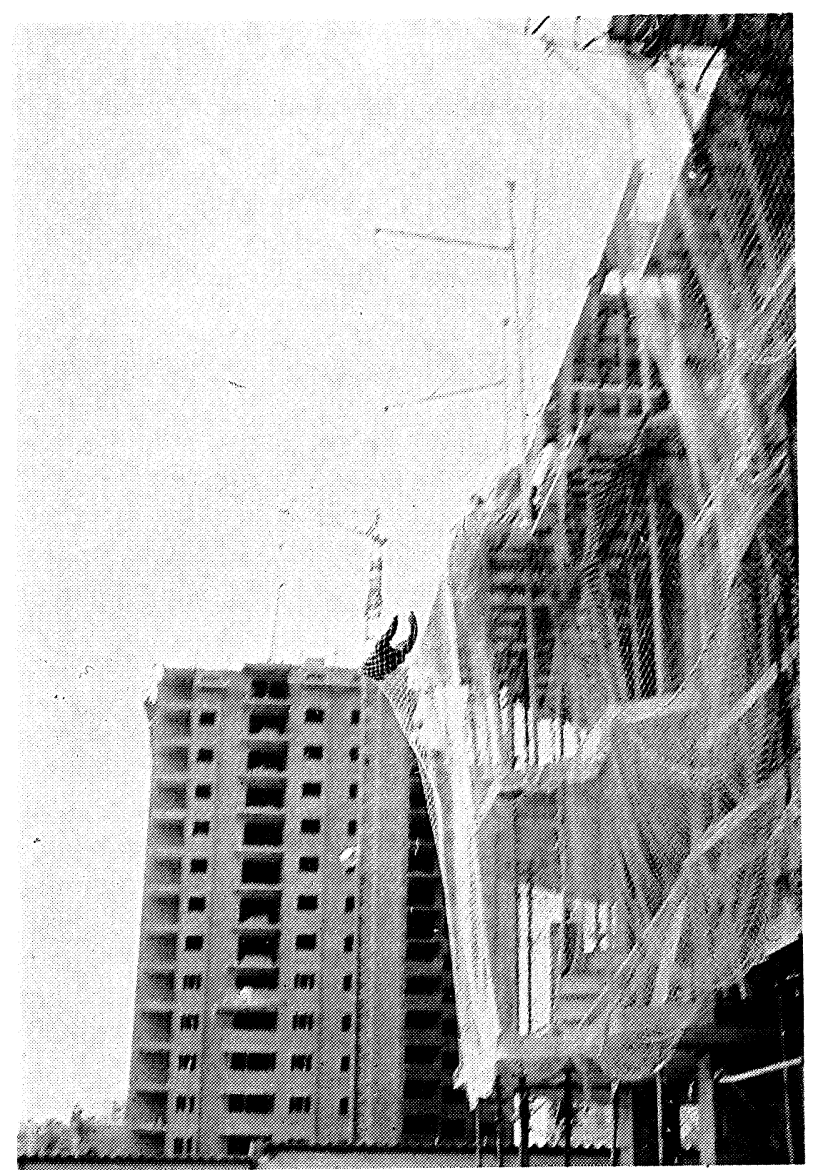

que la actual, la serie de responsabilidades ( $y$ como consecuencia, competencia, derechos y obligaciones) de todos los implicados en el proceso constructivo, que como también se ha visto anteriormente, en la actualidad están tremendamente difuminadas en alguno de los casos, y excesivamente concretadas en lo que a responsabilidad se refiere y no en lo que a competencias respecta, en otros.

\subsection{Actuación de la Administración}

Al hilo de lo anterior, el papel que la Administración debe jugar en todo este campo es prioritario y fundamental, dado que nadie sino ella puede regular toda esa nueva legislación y definir perfectamente las responsabilidades y competencias antes mencionadas.

Es decir, debería de realizarse una mayor concienciación de la clase trabajadora, ya que de ellos mismos en, primer lugar, debería partir la auténtica labor prevencionista, dado que son los primeros protagonistas en sufrir las consecuencias del accidente; y así en grado ascendente, pasando por los mandos intermedios, regulando mucho más claramente $y$, sobre todo, ejerciendo una más eficaz labor de vigilancia en lo que se refiere a la implantación y funcionamiento de los Comités de Seguridad en las obras y de los Vigilantes de Seguridad. Concienciación que atañe también a las empresas constructoras, en el sentido de que, si bien la Seguridad puede costar un dinero inmediato, a la larga es evidente que, no solamente a título humano, sino incluso económicamente, es rentable con las lógicas reducciones de las cuotas en las pólizas de seguros.

Lo mismo reza para el proyectista de la edificación, a quien de alguna manera y sin coartar su libertad a la hora de proyectar, se le debería también concienciar para que aquello que proyecta lo haga pensando en su futura ejecución y previniendo, en lo posible, los riesgos que dicha realización puede llevar anejos.

Pero sobre todo, donde entendemos que la labor de la Administración podría ser más rentable en este tema, sería sin duda en dar mayor auge y responsabilidades al Plan Nacional de Higiene y Seguridad en el Trabajo, dotándolo de mayores medios para que pudieran acceder a un mayor número de obras con su labor de asesoramiento en la prevención de accidentes.

\subsection{El estudio de Seguridad}

En el sentido de lo anteriormente expuesto, entiendo que en esta evolución podría jugar un papel básico el denominado Estudio de Seguridad, que debería implantarse de forma obligatoria en todo Proyecto de construcción.

Desde hace 8 ó 10 años en que viene tratándose este tema, en cuantas reuniones, simposios, congresos, etc, se han realizado sobre la materia, se ha llegado a la conclusión prácticamente unánime de todos los sectores implicados, de que el mejor método preventivo de accidentes en la construcción sería la correcta ejecución y puesta en práctica del mencionado Estudio de Seguridad.

\subsubsection{Definición del Estudio de Seguridad}

Será el instrumento legal que defina las medidas de seguridad e higiene que sea preciso adoptar para la construcción de una obra con el menor riesgo de accidentes posibles. Describirá detalladamente para cada obra los medios preventivos a emplear, regulará las actuaciones y delimitará las responsabilidades de las partes que intervienen en el proceso edificatorio $y$ valorará el costo de todas estas medidas.

Para la redacción de este documento obviamente se partirá de cada proyecto de obra, con el cual el estudio de Seguridad tendrá que ser coherente, aun cuando sea independiente del mismo.

Veremos a continuación las mejoras que podría aportar este documento a la situación anteriormente descrita.

\subsubsection{Aspectos puramente técnicos de prevención}

Al estudiar previamente a su ejecución inmediata los riesgos que conlleva un determinado trabajo, se pueden barajar distintas soluciones y elegir la más eficaz, segura y económica, estableciendo también el orden de prioridades de las protecciones a emplear, las posibles fases de su montaje, etc. 
A pesar de la prevención, es obvio que el accidente puede sobrevenir. Para este caso, el Estudio deberá templar también las mejores medidas de paliar los efectos del accidente, a través de un adecuado plan de evacuación, la provisión de primeros auxilios en obra, dotación del botiquín y de los posibles servicios médicos y sanitarios, etc. Además de todo esto, deberá ser un documento lo suficientemente explícito para que los técnicos que intervienen en la obra, tanto la Dirección Facultativa como Jefes de Obra y mandos intermedios $y$, por supuesto, la propia empresa constructora, puedan acudir a él para saber claramente los riesgos sucesivos que se puedan presentar en la ejecución de la obra y la medida concreta y específica que se debe adoptar para prevenir dicho riesgo. Ello sin perjuicio, evidentemente, de que en el transcurso de la obra puedan introducirse cuantas alteraciones o soluciones alternativas se crean oportunas, siempre que las mismas sean adoptadas por consenso de las partes implicadas.

\subsubsection{Delimitación de competenmcias y responsabilidades}

Estas, al venir reguladas conforme a la normativa legal en el Estudio de Seguridad, constituyen por una parte una base importante de prueba frente a la jurisdicción, en caso de ocurrir el accidente y siempre que cada una de las partes implicadas haya cumplido con lo determinado para cada cual en el Estudio; y por otra, un lugar común donde acudir cada una de las partes a detectar cuál debe ser su actuación frente al riesgo del accidente y la forma de prevenirlo. Así pues, los directamente implicados en el proceso, como son los propios trabajadores y sus órganos de representación y control, los técnicos y mandos intermedios, la empresa como entidad y la Dirección Facultativa, tendrán, en relación con la obra en cuestión, perfectamente delimitadas sus actuaciones $y$, por lo tanto, claramente definidas sus posibles responsabilidades ante el no cumplimiento de lo indicado en el Estudio y ante el acaecimiento del accidente, sea éste debido a una carencia de cumplimiento, a simple fallo fortuito o a causas de fuerza mayor.

De este modo, también la Administración, mediante sus obligados mecanismos de control, inspección y vigilancia, podrá detectar más claramente el cumplimiento o no de las normas establecidas; primero, sabiendo de la existencia o no del Estudio de Seguridad, sin el cual no dará el permiso oportuno para iniciar la obra; y después, pudiendo seguir su cumplimiento e informar a la jurisdicción con más objetividad caso de producirse el accidente, porque conocerá las partes del Estudio que no se han cumplido.

\subsubsection{Aclarar el costo de las medidas de Seguridad e Higiene}

Este es, sin duda, uno de los factores claves por los cuales no se consigue la suficiente seguridad: porque supone un gasto $y$, por lo tanto, un incremento en el costo de ejecución de la obra. $Y$ aunque, como se ha dicho, este costo está implícitamente integrado en cada partida de obra (como medios auxiliares para la

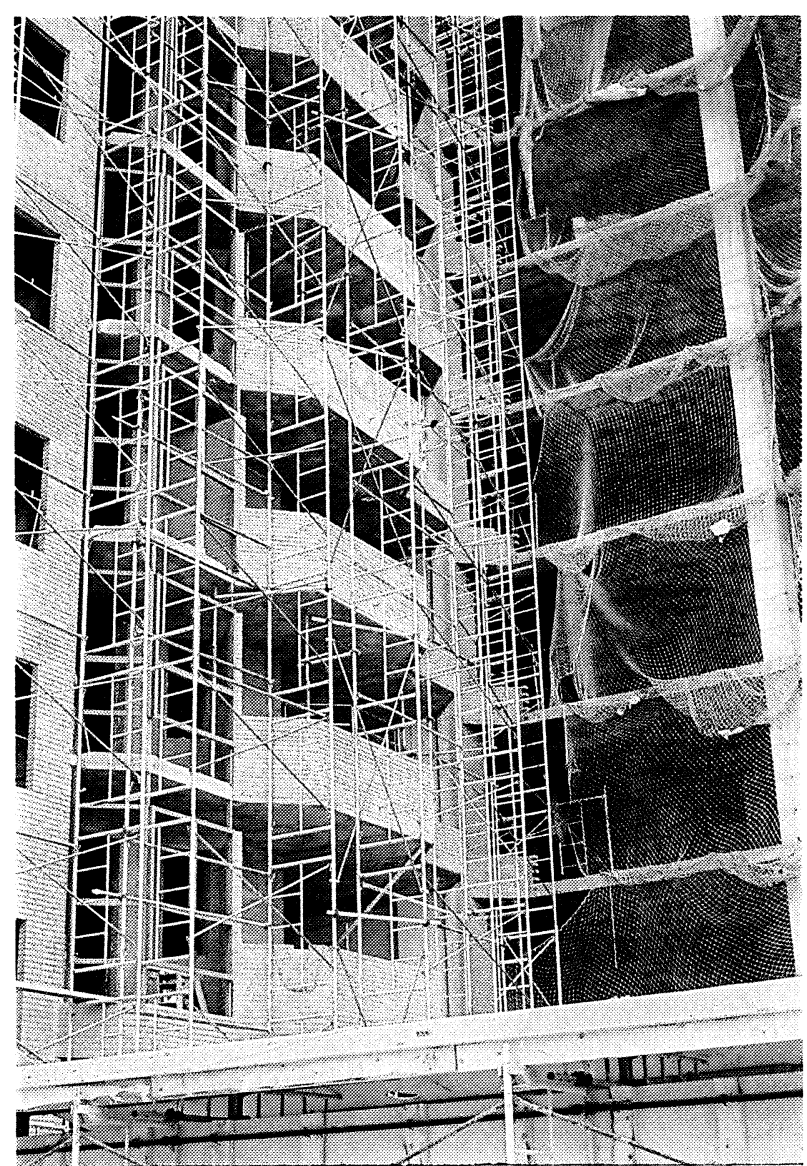

ejecución de la misma) la realidad es que la no aplicación de medidas de seguridad - aparentemente $y$ al menos de forma inmediata - supone un ahorro, aunque sea a costa de transgredir las claras normas existentes al respecto y de provocar consecuencias muy negativas. En este sentido también podría ser clave la existencia del Estudio de Seguridad, dado que, al valorar los medios de seguridad a emplear con independencia del resto de la ejecución de la obra, el costo de los mismos se vería claramente reflejado y sería medible y certificable, como el resto de la ejecución de la obra, cuando se empleasen dichos medios.

Conviene, pues, dejar muy claro que la implantación del Estudio de Seguridad no supondría ningún aumento del costo de la construcción actual, sino simplemente la obligatoriedad de hacer eficaces unos costos que ahora se suponen, se presupuestan $y$, como consecuencia, se perciben, aun cuando no siempre se adoptan las medidas que teóricamente los originan.

\subsection{Situación legal actual del Estudio de Seguridad}

\subsubsection{Antecedentes}

Ya en marzo de 1979, promovidas por el Ministerio de Trabajo, se celebraron unas reuniones entre todos los estamentos implicados para la posible redacción de unos acuerdos de principio tendentes a elaborar una normativa que desembocara en la implantación de lo que entendemos se denominó Proyecto de Seguridad. 
Las diferencias de criterio entre profesionales, Sindicatos y Patronales, no hicieron posible ninguna base de acuerdo, y tales reuniones, sin causa justificada, dejaron de celebrarse.

Posteriormente, el entonces Instituto Territorial de Higiene y Seguridad del Trabajo de Madrid, convocó una serie de Mesas Redondas para tratar el tema, pero por la irregular representatividad de los asistentes y la falta de objetivos claros tampoco cuajaron en casi nada positivo.

Como consecuencia de estas iniciativas, el Colegio Oficial de Aparejadores y Arquitectos Técnicos de Madrid decide la continuidad del tema y promueve una Mesa Redonda, con base en el mismo sentido de la posible mejora de las condiciones de trabajo, mediante la implantación del Proyecto de Seguridad como obligatorio. Esta Mesa se celebró el 30 de junio de 1980.

\subsubsection{Iniciación del proceso legis/ativo}

Las conclusiones fueron presentadas formalmente en el Ministerio de Trabajo el 16 de junio de 1981, solicitando de la Administración su regulación legal, en la forma oportuna. De forma paralela y en el mes de mayo del mismo año, el Grupo Parlamentario Socialista del Congreso de los Diputados presentaba ante la Mesa de dicha Cámara una Proposición no de Ley en la que se instaba al Gobierno a la promulgación de una norma que hiciese obligatoria la existencia de un Estudio de Seguridad e Higiene en el Trabajo como anexo al Proyecto de obra.

El 21 de abril de 1982, la Comisión de Política Social y de Empleo del Congreso de los Diputados, aprobaba dicha proposición no de ley e instaba al Gobierno a que, en el plazo de tres meses, desarrollase la legislación oportuna para establecer la obligatoriedad de que, en todo proyecto de obra y adjunto al mismo, se incluyera un Estudio de Seguridad e Higiene en el Trabajo de la obra, coherente con el contenido del Proyecto. En el posterior articulado de la proposición se recogen literalmente, sin añadir ni quitar nada, las conclusiones a las que habían llegado la Mesa Redonda convocada por el Colegio de Aparejadores, presentadas el año anterior en el Ministerio de Trabajo.

El Gobierno, en cumplimiento del mandato del Congreso, desarrolló un Proyecto del Real Decreto Ley en los meses posteriores. Desgraciadamente, este proyecto no recogía ni el espíritu ni la forma esencial de la proposición no de ley.

Con la disolución de las Cortes y la convocatoria de elecciones anticipadas, en septiembre del 82 , este asunto quedó en suspenso.

\subsubsection{Situación actual}

Conformada la actual legislatura, el nuevo Gobierno socialista ha redactado otro Proyecto del Real Decreto Ley que se ajusta más a las proposiciones solicitadas y que, en la actualidad, se encuentra en período de información por parte de las entidades afectadas.

En este documento básicamente se establece la obligatoriedad de que a todo proyecto de obra de nueva planta, ampliación o reforma, se incorpore un Estudio de Seguridad e Higiene en el Trabajo que desarrolle la problemática específica de la seguridad, siendo éste un requisito indispensable para el visado del Proyecto por el Colegio Profesional correspondiente y para la concesión de la licencia de construcción por parte de los Ayuntamientos.

El Estudio deberá contener una Memoria descriptiva de los procedimientos y equipos técnicos a emplear, así como de los riesgos y enfermedades profesionales que puedan darse en la ejecución de la obra; un Pliego de Condiciones particulares en el que se tomarán en consideración las normas legales reglamentarias; Planos que contendrán los esquemas y gráficos necesarios de las medidas preventivas a adoptar; Mediciones de las unidades en relación con las medidas de Seguridad e Higiene y una valoración, en forma de Presupuesto, de las mismas.

Adjudicada la obra, el contratista de la misma redactará un Plan de Seguridad e Higiene que adaptará el Estudio de Seguridad a las características propias de maquinaria y medios auxiliares con las que vaya a realizar la obra. Plan que deberá ser aprobado por la Dirección facultativa de la obra, previamente al comienzo de la misma.

Se establece la existencia de un libro de incidencias en cada obra (donde se anotarán las circunstancias que acompañen al desarrollo del Estudio y del Plan de Seguridad) y se regula el funcionamiento de las diversas copias de las hojas del libro, que se deberán entregar a la Inspección del Trabajo, a los Comités o Vigilantes de Seguridad de la obra, a la Dirección Facultativa de la misma y a la propia empresa constructora.

Por último, se indica que los costos de las partidas de Seguridad valorados en el Presupuesto del Estudio, sean abonados mediante certificaciones visadas por la Dirección Facultativa y por la propiedad de la obra.

Es de esperar que este Proyecto del Real Decreto Ley, una vez informado por las partes a las que se les ha dado audiencia y con las modificaciones y ampliaciones que resulten precisas, verá de una forma definitiva la luz del Boletín Oficial del Estado en un próximo futuro, culminando de esta manera largos años de conversaciones y aspiraciones por parte de todos los que, de una u otra forma, intervenimos en el proceso constructivo.

\section{CONCLUSION}

He intentado hasta aquí exponer una breve panorámica de cuál es la situación actual de la Seguridad e 
Higiene en el Trabajo de la Construcción en nuestro país, con un diagnóstico - bajo mi punto de vistadesgraciadamente negativo, pero con una viva esperanza de que la situación ya ha comenzado a cambiar, dado que desde la Administración y hasta la última de las entidades que agrupan a las personas que intervenimos en el proceso edificatorio, estamos haciendo un esfuerzo realmente importante porque ello sea así.

Pero debemos ser conscientes que el camino para llegar a la erradicación del accidente es largo y, sobre todo, que debe recorrerse con el esfuerzo y apoyo de todos los que intervenimos en el bello arte de construir, revistiéndonos de un auténtico espíritu prevencionista en las acciones que cada uno desarrollamos.

Que el obrero tenga en cuenta que su vida o su integridad física vale más que esa posible incomodidad por el medio de protección personal o ese minuto que cree que gana al no emplear esa protección colectiva; que los Sindicatos mentalicen a los obreros de que ésta debe constituir una de sus primeras reivindicaciones; que los mandos interme- dios en obra sepan exigir a la empresa y a los trabajadores el empleo de las medidas de protección; que los empresarios dispongan en obra de los elementos auxiliares necesarios para adoptar las medidas de protección colectiva y los materiales necesarios para cubrir las protecciones personales $y$ que se convenzan de que esos costos que imaginan se ahorran por no usar dichos elementos, los pagan con creces en primas elevadas de seguros y en atrasos e irregularidades cuando se produce un accidente en la obra; que los técnicos al frente de las direcciones de las obras tengamos siempre presente nuestra responsabilidad y recordemos permanentemente, con nuestra vigilancia y órdenes, la necesidad de cumplir la normativa existente; que el proyectista piense a la hora de diseñar que la obra que él imagina va a ser realizada por seres humanos y no por ángeles o seres alados y, por último, que la Administración extreme las medidas de vigilancia, redacte las normas adecuadas y dote de los medios necesarios a los Organismos encargados de estas materias.

En definitiva, que todos pensemos que una vida humana y la integridad de todas las demás, bien valen nuestro esfuerzo.

\title{
CUESTIONARIO
}

\author{
Federación Estatal de Madera, Construcción y Afines del Sindicato \\ UGT (FEMCA - UGT)
}

- ¿Cuál es, a su entender, la situación actual de la seguridad en el trabajo de la construcción en España?

- La Construcción es la actividad económica que mayor número de accidentes registra y también es donde el mayor número de estos accidentes resultan mortales. Creo que este dato, confirmado en todas las estadísticas, puede servir para definir la situación actual como dramática.

- ¿Entiende que los sindicatos aportan el suficiente esfuerzo para la mejora de las condiciones de seguridad? ¿En qué hechos concretos se traduce?

-Entiendo que los Sindicatos vienen aportando, desde su legalización, el máximo esfuerzo posible. Pero todavía luchamos contra la inercia que suponen determinadas actitudes empresariales y de la Administración que, poco a poco, se van venciendo gracias a una labor diaría de concienciación de los trabajadores y de acción reivindicativa constante en los centros de trabajó en las mesas de negociación y en los organismos públicos.

Én cuanto a hechos concretos, destacaría la labor que UGT Ilevó a cabo durante la legislatura anterior enviando al Parlamento, a través del Grupo Parlamentario Socialista. la proposición no de Ley que implantará la obligatoriedad de los Estudios de Seguridad en todos los proyectos; la proposición de Ley sobre el amianto y toda una larga serie de preguntas al Gobierno sobre accidentes laborales en e sector:

Esta labor debe plasmarse en realidades durante este año y, en ese sentido, UGT ha propuesto al Gobierno la iniciativa de lanzar una campaña especifica sobre la Seguridad en la Construcción, que se desarrollará durante 1983 y en la que. como ayuda a la labo fundamental del Instituto de Seguridad e Hígiene en el Trabajo, se invitará a participar a empresarios, téenicos y centrales sindicales Ya han aceptado asumir esta campaña los dístintos departamentos implicados en el tema e, inmediatamente, se iniciará con toda la intensidad necesaria

- ¿Én qué medida entiende que podría mejorar la seguridad en la construcción la implantación del proyectado Estudio de Seguridad, a implantar como obligatorio en todas las obras?

- En primer lugar, la experiencia de países desarrollados demuestra que se trata de una medida efectiva. Y en España aportará elementos esenciales para reforzar la prevención. Elementos tales como la simplificación y clarificación de la actual marańa legal para. empresarios y trabajadores, el apoyo que supondrá para los técnicos sobre todo en cuanto afecte a su responsabilidad y atribuciones, la garantía de los recursos económicos necesarios. En UGT estamos absolutamente convencidos de que sólo puede conseguirse una efícaz prevención integral mediante la planificación, puesta en práctica, seguimiento y control de medidas de seguridad, integradas en el proceso productivo a través de la inclusión de estas materias desde la misma concepción del provecto. 


\section{Comisiones Obreras \\ Sindicato Industria Construcción \\ Secretaría de Seguridad e Higiene \\ Sindicato Provincial de Construcción de Comisiones Obreras Gerardo de Gracia Pastor}

\section{- ¿Cuál es, a su entender, la situación actual de la seguridad en el trabajo de la construcción en España?}

-Deficiente y negligente. En cuanto que, desde la Administración y desde las empresas se conoce perféctamente toda la problemática que yo denominaría 'caótica"' y no sólo no se está haciendo nada o muy poco por solucionarlo, sino que ni siquiera se cumplen por parte de las empresas o se hace cumplir por parte de la Administración (Inspectores, Técnicos de Insht) lo establecido por ley.

Normas y Leyes que desde una perspectiva de sindicato de clase juzgamos como mínimos y, por supuesto, insuficientes.

Basten dos datos:

- Los accídentes mortales en el centro de trabajo se están manteniendo año tras año: 1980: 234 ; 1981 : 230; 1982 Iprímer semestre): 113 . (Datos referidos a toda España)

- Y relacionando los accidentes mortales con la población activa expuesta, resulta una tasa, a los 10.000 trabajadores, en aumento: 1980: $2,12,1981: 2,40$.

A través de los Informes de los Inspectores en la verificación de las circunstancias en que se han producido los accidentes mortales. resulta una cantidad alta de infracciones.

_. Entiende que los sindicatos aportan el suficiente esfuerzo para la mejora de las condiciones de seguridad? ¿En qué hechos concretes se traduce?

- Teniendo en cuenta que no tenemos el mínimo apoyo ni económico, ni legislativo, ni institucional y con los agravantes de la subresión de plantillas fijas, contratación temporal por tres meses, los destajos y ritmos de trabajo, modestamente opinamos que e Sindicato de CC. 00 de la Industria de Construcción está haciendo bastante más de lo que le corresponde.

Estamos llevando (aunquie, de momento, sólo en algunas provincias):

- un seguimiento estricto de cada accidente mortal o grave.

- asistimos a cursos formativos.

- constituimos Comités de Seguridad e Higiene.

- realizamos continuas denuncias por deficiencias en seguridad o higiene a través de Delegados y Comités

- aseseramos y formamos a trabajadores y delegados en las técnicas modernas de seguridad.

Por ejemplo, hemos repartido más de 400 juegos de fichas sobre andamios colgados-tubulares y de borriquetas, que se han editado desde el INSHTS.

A veces se espera de nosotros una cierta labor de presión en exigencia de medidas o responsabilidades. Y lo hacemos en determinados casos. Pero muchas veces, nos vemos dificultados porque no tenemos delegados en la obra y, frecuentemente, por la conciencia de culpabilidad que tienen las empresas que les lleva a ponernos trabas a nuestra labor y verificación

- ¿En qué medida entiende que podría mejorar la seguridad en la construcción la implantación del proyectado Estudio de Seguridad, a implantar como obligatorio en todas las obras?

- Si existiera un presupuesto especifico no se podría escamotear, como ocurre ahora, cuando constituye uno de los márgenes del beneficio empresarial aunque vaya incluido en los costos mano de obra indirecta y costos auxiliares.

Desde el comienzo de la obra debería programarse la seguridad, haciendo frente a los riesgos que se van a presentar en cada fase y unidad de obra.

Debería obligarse a los mandos intermedios de las empresas a incluir la seguridad en sus órdenes de trabajo advirtiendo a los trabajadores de los riesgos que corren, con lo cual se contribuiría a su formación.

Pero. para que todo ello surtiera efecto, se tendría que hacer un plan conjunto entre todos los agentes implicados en la obra

- trabajadores y sus representantes.

- cuadros medios y personal de mando.

- dirección facuitativa y proyectista.

- Administración y mutuas de Seguros:

Comisiones Obreras de la Industria de la Construcción está cubriendo una verdadera labor social v no se nos reconoce, ni apova y. por supuesto, no se nos recompensa a pesar de que nuestro trabajo redunda en favor de toda la sociedad y, en concreto, en favor de los tamiliares de afectados por los accidentes, especialmente mortales.

Nuestro trabajo se conereta en los acciéentes mortales en el centro de trabajo en avisar a la lnspección cuando se produce el accidente en el tajo.

Sirva de ejemplo los datos de Madrid y provincia:

- año 1980. 35 accidentes mortales:

- año 1981: 32 accidentes mortales:

- año 1982: 38 accidentes mortales 


\section{Fernando de la Portilla presidente de la Comisión de Seguridad del SEOPAN Asociación de empresas constructoras de ámbito nacional}

- ¿Cuál es, a su entender, la sítuación actual de la seguridad en el trabajo de la construcción en España?

- La seguridad en el trabajo de la construcción en España, a la luz de la estadística, ha mantenido una línea de mejora durante el último quinquenio, reduciendo notablemente el número de síniestros laborales y el de accidentes mortales, en el conjunto del sector.

Dado que el fenómeno general del desempleo ha ínfluido especialmente en la construcción y podría enmascarar los resultados, es necesario utilizar los Indices de Incidencia, en los que la dísminución de puestos de trabajo no influye en aquéllos. Así, el lindice de Incidencia relacionado con el número de accidentes:

N. total de siniestros $/_{N}^{\circ}$ de trabajadores X 100 , en los años 1977 a 1981 , pasó en la Construcción de 12.6 a 8.7 y el de síniestros mortales: $N^{\circ}$ de siniestros mortales $/ N^{\circ}$ de trabajadores $X 100.000$, en el mismo período, se redujo de 29,4 a 24,00 . Todo ello según los datos oficiales elaborados por el Instituto Nacional de Seguridad e Higiene en el Trabajo.

En relación con mi conocimiento directo del tema (datos de SEOPAN y de AGROMAN E.C.S.A.), he de hacer constar la evidencia de ún claro avance preventivo, tanto en actuación técnica frente a los riesgos profesionales, como en sensibilización colectiva. Elio no quiere decir, ni mucho menos, que se hava alcanzado el nivel óptimo en esta materia, pero sí que la tendencía mantenida resulta esperanzadora.

_- ¿Entiende que las Asociaciones Patronales aportan el suficiente esfuerzo para la mejora de las condiciones de Seguridad? ¿En qué hechos concretos se traduce?

- No creo que de ninguna organización estatal, patronal o sindical, pueda decirse que aporte "suficiente" esfuerzo para la mejora de las condiciónes de seguridad. Ello supondría la erradicación de los accidentes en sus respectivas parcelas. Refiriéndome exclusivamente a la Comisión de Seguridad e Higiene del SEOPAN, a la que pertenezco desde su creación. he de confesar que estamos muy lejos de alcanzar esa utopía. Sin embargo, sí hemos realizado positivas aportaciones para el mejoramiento en la prevención de los riesgos profesionales de la Construcción

Enunciaré, telegráficamente, algunos hechos concretos:

- Imparte numerosos cursos formativos que han proporcionado una mentalidad preventiva a cientos de Jefes de Obra y Mandos Intermedios de empresas pertenecientes al SEOPAN.

- Elabora fichas técnicas de prevención para los distintos trabajos realizados en la edificación y en obras civiles. Mantiene, asimismo una continua información y asesoramiento a las empresas asociadas sobre la dinámica de los temas que, en materia de seguridade higiene, pueden afectarles.

- En nuestras 'Primeras Jornadas de Seguridad en la Construcción' 11971 ) presentamos, por primera vez en España la filosofía de la "Seguridad Integrada". Muy poco después, algunas de nuestras empresas iniciaron la elaboración de los 'Proyectos de Seguridad" primer camino hacia la seguridad integrada cuyos buenos resultados consiguieron que adquirieran carta de naturaleza en la mayoría de las grandes obras de construcción.

- Ha organizado "Jomadas de Seguridad" sobre la problemática preventiva de la Construcción: trabajos en altura. excavaciones demoliciones, planes de seguridad, etc. Los trabajos presentados y las conclusiones obtenidas, han sido editados y dífundídos entre los organismos especializados de España y del extranjero

- Contribuye con cursillos y conferencias a extender la formación preventiva entre los universitarios profesionalmente más ligados a la Construcción: Colegio de Aparejadores y Arquitectos Téenicos, Escuela de Ingenieros Técnicos de Obras Públicas y otras.

- Colabora intensamente con el Comité Internacional de AISS para la Prevención de Riesgos Profesionales en la Construcción, cuyo orgárísmo le ha concedido la Secretaría Técnica de dos grupos internacionales de trabajo: "Señalización en Obras' y "Redes de Protección", participando en otros tales como "Elementos de Seguridad en las Grúas". "Productos Bituminosos". "Sistemas de Elevación en Obras": etc.

- Participa activamente con ponencias, comunicaciones, relatores y coordinadores, en congresos, coloquios, asambleas y mesas redondas sobre Prevención de Ríesgos Profesionales. de ámbito nacional e internacional.

- Mantiene relaciones de estrecha colaboración con las asociaciones privadas de prevención en otros sectores laborales y con los organismos oficiales (Ministerio de Trabajo, IN.S. H.T. etc.)

- IÉn qué medida entiende que podía mejorar la seguridad en la construcción la implantación del proyectado Estudío de Seguridad, a implantar como obligatorio en todas las obras?

- La implantación de un Estudio de Seguridad como anexo al Provecto de Obra, supone nada menos que institucionalizar la preocupación preventiva en la mente del proyectista. Si a ello añadimos la necesidad de un Plan de Seguridad, elaborado por el contratista, que traduzca la filosofía del Estudio de Seguridad a sus procedímientos de trabajo y medios técnicos dentro de un presupuesto independiente del general y no sujeto a licitación, entendemos que puede constituir un procedimiento decisivo para alcanzar la mejora general de la prevención de los riesgos profesionales en la Construcción.

G SEOPAN ha defendido desde hace muchos años, la filosofía que inspira este sistema, tanto frente al Ministerio de Trabajo como en discusiones de matiz, con el Colegio de Aparejadores, los Sindicatos y con el Instituto Nacional de Seguridad e Higiene en el Trabajo, habiéndose llegado, afortunadamente, con estos tres ultimos organismos, al total acuerdo en la redacción de un texto final que coincide fundamentalmente con la proposición no de Ley, posteriormente aprobada por el Parlamento (abril de 1982 ) y actualmente pendiente de desarrollo normativo por el Gobierno. 


\section{Manuel Aguirre Bellver presidente de AECOM (Asociación de Empresas de la Construcción de Madrid), integrada en CNC (CEOE)}

- ¿Cuál es, a su entender, la situación actual de la seguridad en el trabajo de la construcción en España?

- La situación actual es francamente buena y sigue en línea de mejora, como lo demuestran los datos estadísticos más recientes.

- ¿Entiende que las Asociaciones Patronales aportan el suficiente esfuerzo para la mejora de las condiciones de seguridad? ¿En qué hechos concretos se traduce?

- Las asociaciones patronales han colaborado intensamente en la dífusión de la normativa vigente sobre Seguridad e Higiene en el trabajo, tanto a nivel nacional como provincial; han prestado su colaboración económica y técnica a las campañas promovidas para combatir la siniestrabilidad laboral y han acogido con el mayor interés todas las propuestas realistas en dicha materia.

- ¿ En qué medida entiende que podría mejorar la seguridad en la construcción la implantación del proyectado Estudio de Seguridad, a implantar como obligatorio en todas las obras?

- Con independencia de los estudios e íniciativas en esta materia por parte de gran número de empresas, el Convenió Colectivo de la Construcción de Madríd del año 1978 establecía, a petición de AECOM. lo siguiente:

¿Cuarta. Las partes contratantes se comprometen a solicitar del Gobierno ... Asimismo también se comprometen a dirigirse a los organismos que resulten competentes para que se articule, como obligatorio, un proyecto específico de seguridad para cada obra con su apartado particular en el presupueston.

Es decir a instancía de esta asociación se recogía por primera vez en un pacto la necesidad de implantar el llamado 'Provecto de Seguridad" en las obras, y este precepto dio lugar a que el Ministerio de Trabajo mantuviera reuniones con las partes interesadas e incluso fuese nombrada una Comisión para el mejor tratamiento del tema

AECOM sigue manteniendo en la actualidad la necesidad del mencionado proyecto.

\section{publicaciones del i.e.t.c.c.}

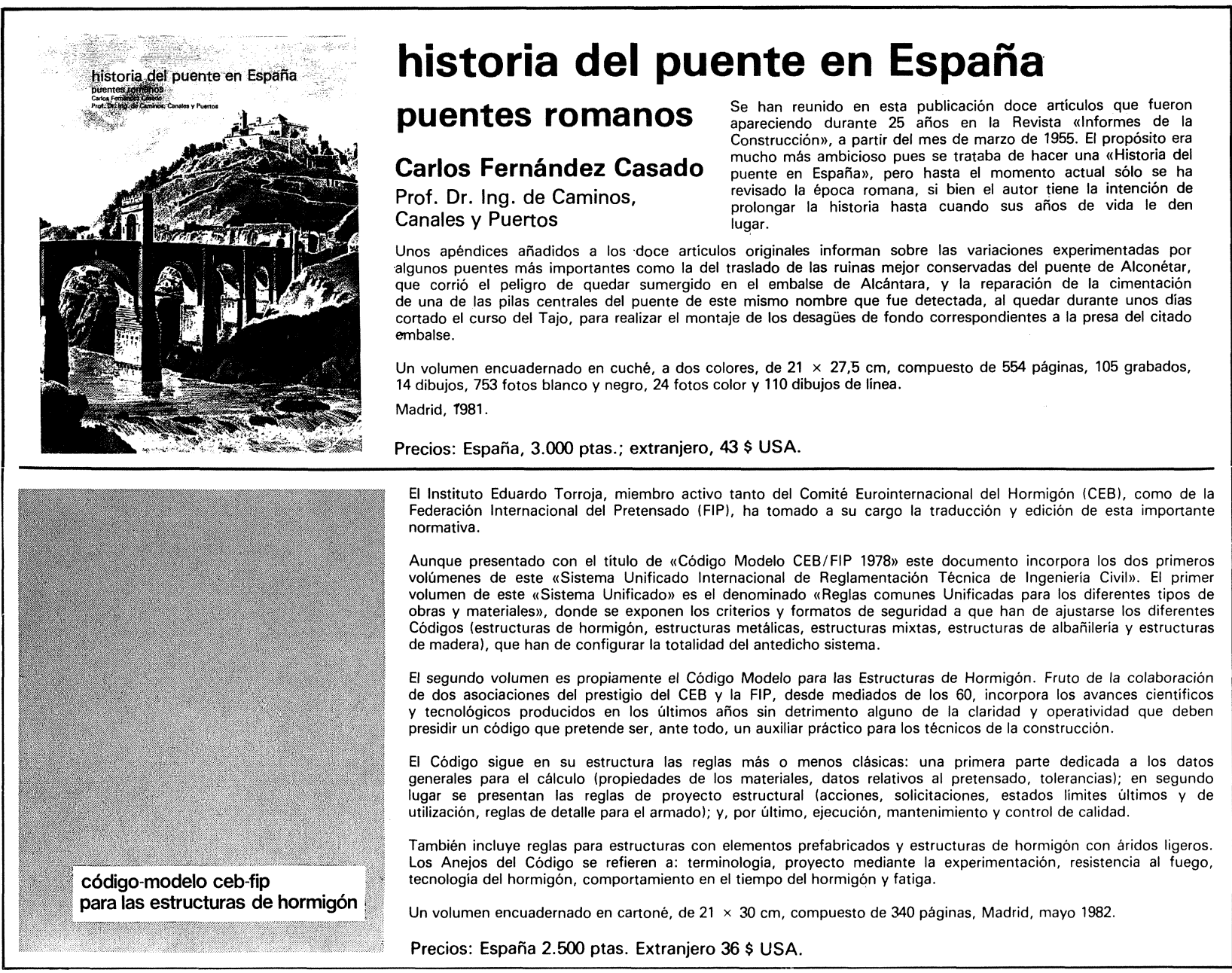

